\title{
Correction to: The Race of I0 Synthetic RNAi-Based Drugs to the Pharmaceutical Market
}

Ricardo Titze-de-Almeida ' • Catherine David ${ }^{2}$ • Simoneide Souza Titze-de-Almeida ${ }^{\text {I }}$

Published online: 7 February 2018

(C) Springer Science+Business Media, LLC, part of Springer Nature 2018

\section{Correction to: Pharm Res}

https://doi.org/10.1007/s I 1095-017-2134-2

The published article contains an error in Figure 5. The term "Atu027" should be substituted by "Patisiran" in figure and legend.

The corrected figure and legend appear below.

The online version of the original article can be found at https://doi.org/l 0. |007/s | |095-0 |7-2 |34-2

$\triangle$ Ricardo Titze-de-Almeida

ricardotitze.unb@gmail.com

Catherine David

http://biotika.com.br

Technology for Gene Therapy Laboratory, ASS I28, ICC Sul, University of Brasília-UnB, Campus Darcy Ribeiro, FAV, Braślia, DF 709 I0-970,

Brazil

2 Av. Pedro Severino Junior, 366, sala 45 e 46 - Vila Guarani, São

Paulo, SP 0431 0-060, Brazil 

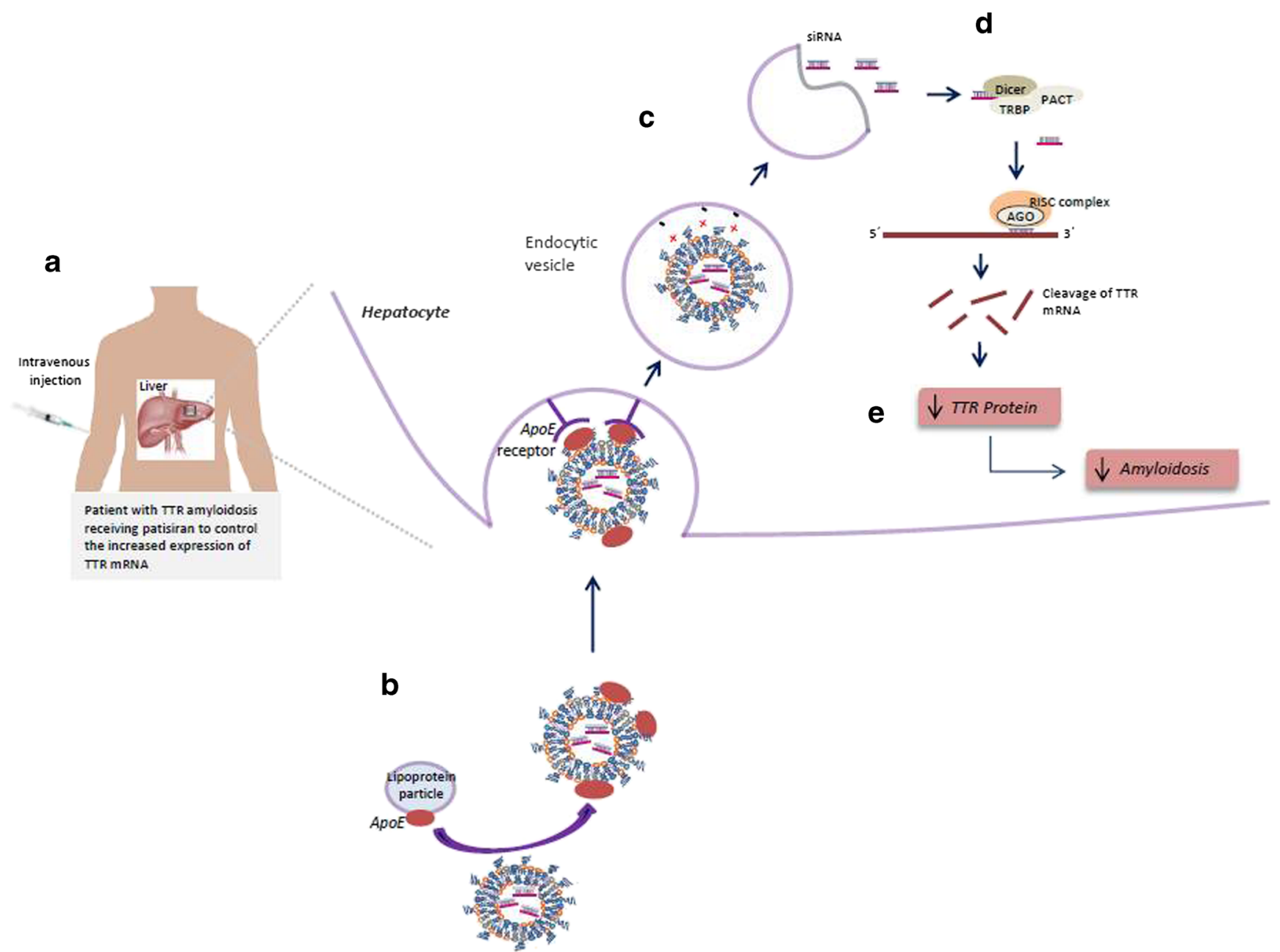

Fig. 5. Rationale on patisiran technology for the treatment of TTR-mediated amyloidosis. (a) Patients with amyloidosis present an increased expression of TTR gene. Patisiran is a TTR-targeted siRNA, formulated in lipid carriers for I.V. administration. (b) Lipid particles coated with ApoE bind to receptors in hepatic cells and are internalized by endocytosis. (c) lonizable lipids of these particles will acquire positive charges by protonation due to the acid pH of endocytic vesicles. Positively charged nanoparticles will bind to negatively charged endosomal membrane, and the fusion of these membranes will finally deliver siRNAs in cell cytoplasm. (d) TTR-targeted siRNAs will bind to complementary sequences in 3' end of TTR mRNA, instead of the traditional CDS region. AGO enzyme of RISC complex will execute TTR mRNA cleavage. (e) Reducing TTR expression will prevent the accumulation of abnormal amyloid proteins in tissues.

AGO - Argonaute 2; ApoE - apolipoprotein E; CDS - Coding sequence region of mRNA; Dicer - a ribonuclease enzyme; PACT - Protein activator of the interferon-induced protein kinase (PKR); RISC - RNA-induced silencing complex; TRBP - HIV-I Trans-activation response (TAR) RNA-binding protein; TTR transthyretin. 